\title{
Speech symptoms associated with early signs of Shy Drager syndrome
}

\author{
CELIA J BASSICH, CHRISTY L LUDLOW, RONALD J POLINSKY \\ From the Speech Pathology Unit and the Unit on Clinical Pharmacology, Office of the Scientific Director, \\ National Institute of Neurological and Communicative Disorders and Stroke Bethesda, Maryland, USA
}

SUMMARY Speech disturbances reflecting impaired laryngeal control were found in ten patients whose autonomic dysfunction was associated with central neurological disease (Shy Drager Syndrome). In contrast, ten patients with progressive autonomic failure without evidence of CNS involvement had no difficulties on speech function tasks in comparison with normal controls. Presence of speech symptoms may aid in the clinical differentiation between patients with pure autonomic dysfunction and those with central neurological involvement.

Progressive autonomic failure may occur in isolation' $^{\prime}$ or in association with central nervous system disorders such as Shy-Drager syndrome or Parkinson's disease.2 Symptoms of autonomic failure include: orthostatic hypotension, constipation, incontinence, anhidrosis, impotence, xerostomia, and impaired vision. In some patients, the autonomic dysfunction may be accompanied by central neurological signs such as ataxia, incoordination, ridigity, bradykinesia, tremor, emotional lability, and regressive reflexes, and is referred to as ShyDrager syndrome. ${ }^{3}$ These other neurological manifestations appear two to five years after the onset of the autonomic symptoms and gradually progress in severity. ${ }^{4}$ Patients with Shy-Drager syndrome may have olivo-ponto-cerebellar atrophy, striatal-nigral degeneration, or a combination of the two. ${ }^{5}$

Biochemical and pharmacological studies have distinguished between these separate clinical syndromes, idiopathic orthostatic hypotension and Shy Drager Syndrome. ${ }^{67}$ Since the prognosis and clinical course differs significantly it is important to differentiate between these two syndromes. Such differentiation is difficult in the early disease stages since similar autonomic symptoms are often present in both disorders prior to the appearance of other neurological abnormalities in the patients with Shy Drager syndrome.

Laryngeal stridor, phonatory disorders, and other

Address for reprint requests: Dr Christy L Ludlow, Speech Pathology Unit, National Institute of Neurological and Communicative Disorders and Stroke Building 36, Room 5A15, Bethesda, Maryland 20205, USA.

Received 17 February 1984. Accepted 17 March 1984 motor speech disturbances are frequent in patients with Shy Drager syndrome. ${ }^{8}$ Respiratory failure requiring tracheostomy may result from bilateral paresis of vocal fold abductor muscles. ${ }^{9}$ Teravainen and $\mathrm{Udd}^{10}$ described one patient whose vocal cord paralysis occurred one year prior to the appearance of both autonomic and extrapyramidal symptoms. Electromyographic studies have indicated denervation of the posterior cricoarytenoid and interaryntenoid laryngeal muscles; marked atrophy of the posterior cricoaryntenoid muscle was found postmortem in Shy Drager syndrome patients. ${ }^{11} 12$

Clinical investigations of speech disturbances have not attempted to differentiate between patients with Shy Drager syndrome and with idiopathic orthostatic hypotension. Linebaugh ${ }^{13}$ found dysarthria in 35 of 80 patients with autonomic failure, while Thomas and Schirger ${ }^{14}$ reported speech disturbances in 11 of 30 such patients whom they studied. Unfortunately, the classification of patients in these studies is unclear. In the present study, experimental tasks assessing speech production were employed and objective measures made of six different speech functions in patients with idiopathic orthostatic hypotension and Shy Drager syndrome. We have distinguished between these patient groups on the basis of the objective speech and phonatory assessment.

\section{Methods}

\section{Subjects}

Ten consecutively admitted patients were included in each of two patient groups, idiopathic orthostatic hypotension and Shy Drager syndrome. All patients were admitted to 
Table 1 Results of examination for signs of autonomic and central nervous system dysfunction in patients with idiopathic orthost hypotension and Shy Drager syndrome

\begin{tabular}{|c|c|c|c|c|c|c|c|c|c|c|c|c|c|c|c|c|c|c|c|c|}
\hline \multirow[b]{2}{*}{$\begin{array}{l}\text { Patient No. } \\
\text { Sex } \\
\text { Age } \\
\text { Duration of Symptoms (yrs) }\end{array}$} & \multicolumn{10}{|c|}{ Idiopathic orthostatic hypertension } & \multicolumn{9}{|c|}{ Shy drager syndrome } & \multirow[b]{2}{*}{ 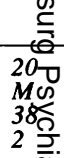 } \\
\hline & $\begin{array}{l}1 \\
F \\
48 \\
18\end{array}$ & $\begin{array}{l}2 \\
F \\
54 \\
13\end{array}$ & $\begin{array}{l}3 \\
M \\
72 \\
12\end{array}$ & $\begin{array}{l}4 \\
M \\
66 \\
9\end{array}$ & $\begin{array}{l}5 \\
M \\
59 \\
9\end{array}$ & $\begin{array}{l}6 \\
F \\
69 \\
8\end{array}$ & $\begin{array}{l}7 \\
M \\
70 \\
6\end{array}$ & $\begin{array}{l}8 \\
F \\
40 \\
5\end{array}$ & $\begin{array}{l}9 \\
F \\
32 \\
3\end{array}$ & $\begin{array}{l}10 \\
F \\
64 \\
2\end{array}$ & $\begin{array}{l}11 \\
F \\
45 \\
10\end{array}$ & $\begin{array}{l}12 \\
M \\
63 \\
10\end{array}$ & $\begin{array}{l}13 \\
M \\
56 \\
9\end{array}$ & $\begin{array}{l}14 \\
M \\
54 \\
6\end{array}$ & $\begin{array}{l}15 \\
F \\
51 \\
6\end{array}$ & $\begin{array}{l}16 \\
M \\
52 \\
4\end{array}$ & $\begin{array}{l}17 \\
M \\
55 \\
4\end{array}$ & $\begin{array}{l}18 \\
M \\
56 \\
4\end{array}$ & $\begin{array}{l}19 \\
M \\
68 \\
3.5\end{array}$ & \\
\hline Constipation & + & + & + & + & + & + & - & + & + & - & + & + & + & + & + & + & + & + & + & \\
\hline Neurogenic bladder & + & - & + & - & + & + & - & + & - & - & + & + & + & + & + & + & + & + & + & \\
\hline Impotence or loss of libido & - & + & + & + & + & - & + & - & - & - & + & + & + & + & + & + & + & + & + & \\
\hline Decreased sweating & - & + & + & - & + & + & - & + & - & - & + & + & - & - & - & - & - & - & - & - \\
\hline Blurred vision & + & - & - & - & + & - & - & + & + & - & - & - & + & + & + & - & - & - & + & \\
\hline Horner's syndrome & - & + & - & + & - & - & - & + & - & - & - & - & - & - & - & - & - & - & - & \\
\hline Ataxia & - & - & - & - & - & - & - & - & - & - & + & + & + & + & + & + & + & + & + & \\
\hline Rigidity & - & - & - & - & - & - & - & - & - & - & + & - & + & - & + & + & - & + & + & $+\bar{c}$ \\
\hline Bradykinesia & - & - & - & - & - & - & - & - & - & - & + & - & + & - & + & + & - & + & + & \\
\hline Tremor & - & - & - & - & - & - & - & - & - & - & + & - & + & + & + & + & + & - & + & \\
\hline Babinski & - & - & - & - & - & - & - & - & - & - & + & + & + & + & + & + & - & + & + & -0 \\
\hline Emotional lability & - & - & - & - & - & - & - & - & - & - & + & + & + & + & + & - & - & - & + & $+c$ \\
\hline Incoordination & - & - & - & - & - & - & - & - & - & - & + & + & + & + & + & + & + & + & - & + \\
\hline Regressive reflexes & - & - & - & - & - & - & - & - & - & & + & + & + & - & + & + & - & + & + & \\
\hline
\end{tabular}

the National Institute of Health for investigation of orthostatic hypotension as previously described.7 Table 1 summarises the clinical charateristics of patients in both groups. The mean ages $( \pm S D)$ of the idiopathic orthostatic hypotension and Shy Drager syndrome patients were 57.5 $( \pm 13.9)$ and $53.8( \pm 8.4)$ years, respectively. Seven of the Shy Drager syndrome patients had clinical signs of striatalnigral degeneration while three exhibited symptoms of olivo-ponto-cerebellar atrophy. Twenty normal controls without history of autonomic or central nervous system dysfunction or speech/language disorders were selected to match each of the patients for sex and within 3 years in age. Medication was discontinued for at least one week prior to testing. Complete medical and neurological examinations were performed independent of the speech recordings. The speech analyses were conducted independently and without knowledge of the results of the medical and neurological examinations.

\section{Recording procedures}

All subjects were able to tolerate sitting in a high backed chair for a 15 minute recording session. Speech was recorded on a Nagra IV-S tape recorder with a microphone 3 inches $(7.5 \mathrm{~cm})$ from the subject's mouth. The sound pressure level of a $1000 \mathrm{~Hz}$ tone recorded at the subject's microphone, was read with a sound level meter for calibration purposes. A thirteen minute instruction tape provided the speech items for imitation including: extended phonations of vowels, imitation of sentences at regular and fast speech rates, rapid repetition of vowels and syllables for 7 seconds, production of vowels and syllables as rapidly as possible after a click, imitation of pitch glide, imitation of intonation contours in a sentence, imitation of four loudness levels, and production of word boundary contrast, for example "blue bell" vs "bluebell." Further details of these tasks are provided in Ludlow and Bassich. ${ }^{15} 16$

\section{Speech analyses}

All speech recordings were analysed acoustically without knowledge of subject identity or diagnosis. Sound spectrograms were measured for time and fundamental fre- $\square$ quency with an $x-y$ digitiser calibrated in hundredths of aO second and Hertz. Graphic Level Recorder tracings were used to measure sound pressure level re: 20 micro Pasch- $\frac{\mathscr{Q}}{\mathbb{Q}} \overrightarrow{ }$ als. ${ }^{17}$ Research assistants performed these measures follow-으 $\mathrm{c}$ ing extensive training to assure a minimum of 0.80 reliabil ity.

Thirty acoustic measures previously found to be valid foro assessing the speech of dysarthric patients, ${ }^{15}$ were made for each subject and are defined in the Appendix. These measures can be subgrouped into six categories:

Rate control Five measures assessed patients' abilities to change speaking rate and to rapidly initiate speech.

Speech articulation Six measures assessed patients' control of movements of oral structures for speech. Some variables assessed differences in speech rate in sounds requiring lip and tongue movement while others assessed the effects of different articulators on the latency of speech initiation.

Voicing control Six variables measured phonatory control and the coordination of laryngeal movements with those of other articulators.

Fundamental frequency control Five measures were made of the maximum range in fundamental frequency (Fo) in speech intonation.

Syllable timing control Three variables assessed patients' control of syllable lengths and pause durations to achieve stress contrasts in speech.

Intensity control Five variables measured the maximum range in intensity and intensity control during speech production. 
Table 2 Mean Z-Scores, range and percent of impaired subjects and results of ANOVAs comparing 2 groups of patients with idiopathic orthostatic hypotension (IOH) and Shy Drager syndrome (SDS)

\begin{tabular}{|c|c|c|c|c|c|c|c|c|}
\hline \multirow[b]{2}{*}{ Acoustic measure } & \multicolumn{3}{|l|}{ IOH group } & \multicolumn{5}{|l|}{$S D S$ group } \\
\hline & Mean Z score & Range & $\begin{array}{l}\text { Percent } \\
{ }^{*} \text { impaired }\end{array}$ & Mean Z score & Range & $\begin{array}{l}\text { Percent } \\
\text { *impaired }\end{array}$ & $F$ & $p$ of $F$ \\
\hline $\begin{array}{l}\mathrm{F}_{\text {o variations in imitation of }} \\
\text { intonation contour } \\
\text { Soft to shout intensity range } \\
\text { Maximum intensity level }\end{array}$ & $\begin{array}{r}-0.27 \\
-0.08 \\
0.37\end{array}$ & $\begin{array}{l}-1.73 \text { to }+3.07 \\
-1.24 \text { to }+1.08 \\
-0.75 \text { to }+1.39\end{array}$ & $\begin{array}{r}40 \% \\
0 \% \\
0 \%\end{array}$ & $\begin{array}{l}-1.86 \\
-3.36 \\
-1.61\end{array}$ & $\begin{array}{l}-2.34 \text { to }-0.37 \\
-6.55 \text { to }-1.02 \\
-5.31 \text { to }+0.06\end{array}$ & $\begin{array}{l}90 \% \\
80 \% \\
50 \%\end{array}$ & $\begin{array}{r}9 \cdot 6 \\
30 \cdot 0 \\
12 \cdot 9\end{array}$ & $\begin{array}{l}0.006 \\
0.001 \\
0.002\end{array}$ \\
\hline $\begin{array}{l}\text { Voicing changes during vowel } \\
\text { repetitions }\end{array}$ & $0 \cdot 36$ & $-2 \cdot 26$ to $+3 \cdot 62$ & $20 \%$ & $-1 \cdot 77$ & -3.39 to -0.66 & $60 \%$ & 10.6 & 0.004 \\
\hline $\begin{array}{l}\text { Voicing changes during } \\
\text { consonant repetitions } \\
\text { Voicing errors for vowels } \\
\text { Voicing errors for consonants }\end{array}$ & $\begin{array}{l}0.81 \\
0 \cdot 31 \\
0 \cdot 21\end{array}$ & $\begin{array}{l}-0.60 \text { to }+2.50 \\
-0.03 \text { to }+0.58 \\
-0.36 \text { to }+0.36\end{array}$ & $\begin{array}{l}0 \% \\
0 \% \\
0 \%\end{array}$ & $\begin{array}{l}-0.58 \\
-3.29 \\
-0.30\end{array}$ & $\begin{array}{l}-1.78 \text { to }+0.42 \\
-5.99 \text { to }-0.74 \\
-1.36 \text { to }+0.29\end{array}$ & $\begin{array}{l}20 \% \\
70 \% \\
10 \%\end{array}$ & $\begin{array}{r}12 \cdot 7 \\
28 \cdot 3 \\
6 \cdot 4\end{array}$ & $\begin{array}{l}0.002 \\
0.001 \\
0.02\end{array}$ \\
\hline
\end{tabular}

*Percent of patients with $\mathrm{Z}$ of $\dot{\mathrm{p}}<0.10$

\section{Results}

To determine whether patients with progressive autonomic failure without evidence of CNS involvement were impaired on measures of speech motor control, the idiopathic orthostatic hypotension patient group and the age and sex matched control group were compared on each of the speech function measures listed in the Appendix. There were a total of $\mathbf{3 0}$ measures grouped according to the six different speech functions of rate control, speech articulation, voicing control, fundamental frequency control, syllable timing control and intensity control. None of the one-way ANOVAs blocking on age with $\log$ data $^{18}$ indicated statistically significant differences $(p<0.02)$ between the two groups on any of the 30 speech function measures. Therefore, the idiopathic orthostatic hypotension group had no difficulties on speech motor control tasks in comparison with normals.

Since the idiopathic orthostatic hypotension and Shy Drager syndrome patient groups differed in age, it was necessary to compute the degree of deviance of each subject relative to their age-matched control group to allow for comparisons between the two patient groups. $\mathrm{Z}$ scores were computed for each patient on each acoustic measure and indicated by what number of standard deviations a patient's score differed from normal and in which direction. $\mathrm{Z}$ scores of patients in the idiopathic orthostatic hypotension and Shy Drager syndrome groups were then compared by computing one-way ANOVAs ${ }^{18}$ for each speech function measure. Statistically significant differences $(p<0.02)$ were found on seven of the thirty measures. The ANOVA results are presented for these seven measures in table 2 . The Shy Drager syndrome patients had more voicing errors and fewer voicing onsets and offsets during vowel and consonant repetitions. Although both groups had reduced $Z$ scores indicating less change in fundamental frequency than normal, the Shy Drager syndrome patients were significantly reduced in comparison with the idiopathic orthostatic hypotension group. The "soft" to "shout' intensity range was also significantly reduced in the Shy Drager syndrome group as was the maximum level of intensity on the loudness imitation task. Although significant differences were found between the idiopathic orthostatic hypotension and Shy Drager syndrome groups on seven of the speech function measures, the mean $\mathrm{Z}$ scores of subjects in the Shy Drager syndrome group were outside of the range of $90 \%$ of the normal controls on only five of these measures. The mean and range in $Z$ scores and the percentage of patients with $Z$ scores in the impaired direction for both patient groups on these seven measures are presented in table 2 . Nine of the 10 Shy Drager syndrome patients had less fundamental frequency variation in sentence intonation than $90 \%$ of the normal controls. Similarly, eight of the Shy Drager syndrome patients were reduced in their maximum intensity range below the normal range, and five were reduced below the normal range in their maximum intensity level. Six of the Shy Drager syndrome patients had fewer voicing changes on vowel repetitions than normal; however, all but two of the Shy Drager syndrome patients had normal numbers of voicing changes on consonant syllable repetition. A similar pattern of impairment on vowels but not on consonants was also found for the two measures of voicing errors.

The $\mathrm{Z}$ scores of the idiopathic orthostatic hypotension paients fell outside of the $90 \%$ normal limit on only two of the acoustic measures. Four of the idiopathic orthostatic hypotension patients had reduced fundamental frequency variation in sentences below normals, although the magnitude of $Z$ scores in the impaired direction was not as great as in the Shy Drager syndrome patients. Two idiopathic orthostatic hypotension patients had 
Table 3 Results of discriminant function analysis with acoustic data between idiopathic orthostatic hypotension and Shy Drager syndrome patients

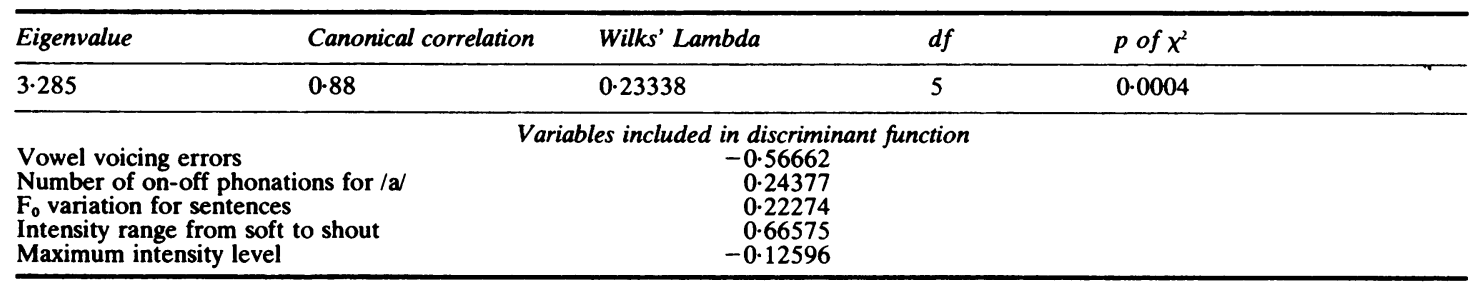

fewer voicing changes on vowel repetitions than $90 \%$ of normals. This reduction, however, was due to an overall reduction in syllable repetition rate in these two patients since neither had a greater number of voicing errors than normal.

Pearson product moment coefficients were computed between the number of years of symptom duration and $\mathrm{Z}$ scores on each of the speech measures to determine whether the degree of speech impairment in Shy Drager syndrome patients was related to symptom duration.

Statistically significant relationships $(p<0.02)$ were found on only two of the measures. The patients with longer symptom durations had slower rates of repetition of the syllable/pa/ $(r=-0.77)$ and were more impaired on bisyllablic repetition/pa-ta/, than on monosyllabic repetition $/ \mathrm{pa} /,(\mathrm{r}=-0 \cdot 72)$. None of the five measures significantly impaired in the Shy Drager syndrome group were related to symptom duration.

To determine whether acoustic measures of speech could correctly identify Shy Drager syndrome patients, $Z$ scores for the five speech measures found impaired in Shy Drager syndrome patients were used to compute a discriminant function (Direct Method); ${ }^{19} \mathrm{~F}_{0}$ variation in Imitation of Intonation Contour, Soft to Shout Intensity Range, Maximum Intensity Level, Vowel Voicing Errors, and Voicing Changes during Vowel Repetitions.
The resultant weighting coefficients are presented in table 3. The discriminant function yielded a Wilks' Lambda of 0.23338 equivalent to a Chi Square with a probability of less than $0 \cdot 0004$. The resultant discriminant function correctly classified all of the idiopathic orthostatic hypotension patients and nine of the 10 Shy Drager syndrome patients. The misclassified Shy Drager syndrome patient had the shortest symptom duration.

The speech performance of idiopathic orthostatic hypotension and Shy Drager syndrome patients with the shortest symptom duration in each group were compared to determine whether these five measures of speech function could accurately identify Shy Drager syndrome patients in the early stages. Five of $\overrightarrow{\vec{D}}$ the Shy Drager syndrome patients had symptom 2 durations of less than five years while only two of the five idiopathic orthostatic hypotension patients with the shortest symptom durations had durations of less than five years. In table 4 , an asterisk is placedo opposite those speech measures where a patient's $\mathrm{Z}$ ? score fell outside the $90 \%$ region of the normal distribution. Three of the Shy Drager syndrome patients in the early stages of disease progression had $\mathrm{Z}$ scores which fell within the impaired region on three or more of the acoustic measures. Only one of the idiopathic orthostatic hypotension patients with a shorter symptom duration was impaired and on only one measure; $F_{0}$ variation on imitation of

Table 4 Acoustic measures on which Z scores are outside of $90 \%$ of normal distribution in five SDS and five IOH patients with shortest symptom durations

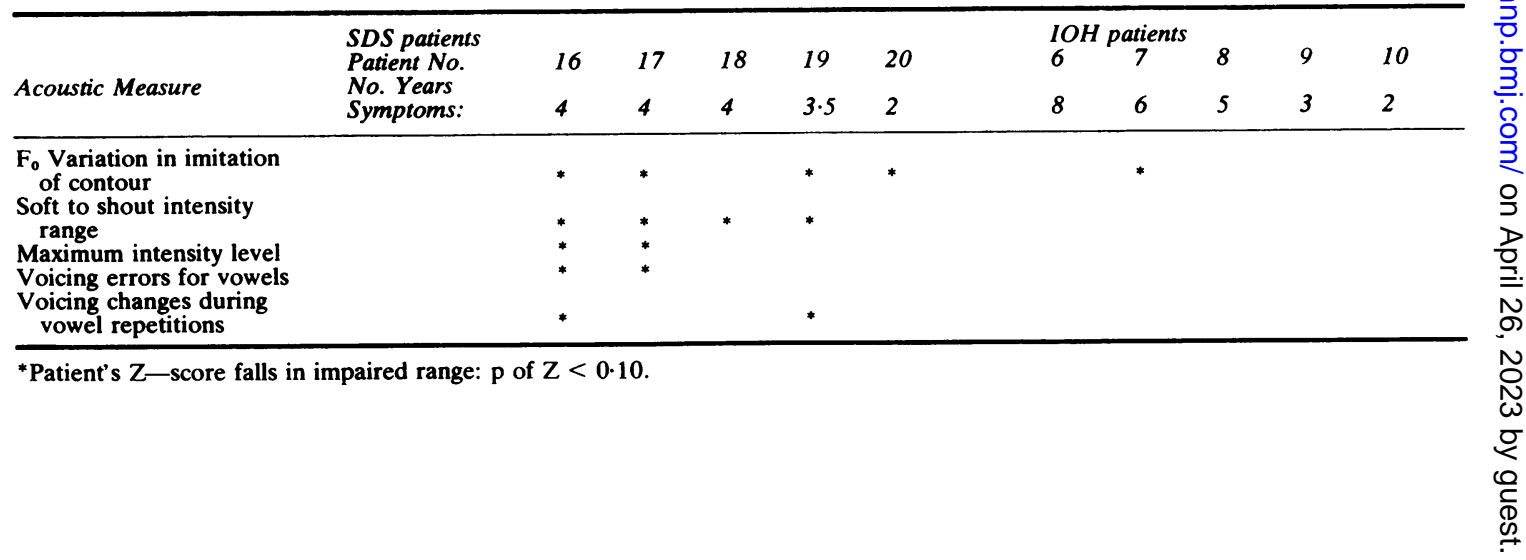


sentence intonation contour. This variable was also impaired in three of the idiopathic orthostatic hypotension patients with longer symptom durations. The intensity range from soft to shout was impaired in four of the five Shy Drager syndrome patients in the early stages of disease progression, yet none of the ten idiopathic orthostatic hypotension patients had impaired $\mathrm{Z}$ scores on this measure. This variable also had the largest weighting coefficient value in the discriminant function.

\section{Discussion}

This study demonstrates that speech disturbances are found only in patients whose automonic dysfunction is associated with central neurological disease. All of the impaired speech function measures assessed phonatory function. Phonatory disorders were evident early in Shy Drager syndrome. Only one Shy Drager syndrome patient was misclassified using a discriminant function analysis containing acoustic measures of phonatory function for speech. This patient had experienced symptoms of autonomic dysfunction for less than two years and was impaired on only one of the speech measures, but reported symptoms of vocal fold fatigue and hoarseness. None of the idiopathic orthostatic hypotension patients reported such speech problems.

The five measures which were impaired in the Shy Drager syndrome group were all measures of the maximum function of the larynx for phonation. For example, the ability to shout was reduced, although the Shy Drager syndrome patients demonstrated a normal intensity level during conversation. Likewise, the ability to achieve a wide variation in fundamental frequency while speaking was impaired. Increased vocal intensity requires the coordination of an increase in vocal fold tension to maintain closure with an increase in airflow. A wide variation in fundamental speech frequency also requires precise control of the laryngeal muscles which adjust vocal fold tension. ${ }^{19}$

Two other measures impaired in the Shy Drager syndrome patients also reflected impaired laryngeal control. The decrease in the rate of phonatory onsets and offsets during vowels and not consonants indicates impaired ability of the laryngeal musculature to interrupt the air flow at the level of the larynx. The intra-oral valving of the airstream during plosive consonants during syllable repetition, however, was unimpaired. The number of voicing errors during vowel repetition but not during consonant syllable repetition indicates that the difficulties in control are primarily in laryngeal function.

Our results suggest that acoustic measures of laryngeal control can be used as a noninvasive adjunct in the clinical evaluation of patients with autonomic dysfunction. Presence of speech symptoms may aid in the differentiation between patients with pure autonomic dysfunction and those with central neurological involvement. Biochemical and/or pharmacological tests require invasive procedures and may not discriminate patients in the early stages of the disease. An increase in speech symptoms developed during the later stages of the disease only in the Shy Drager syndrome patients. Shy Drager syndrome patients with symptom durations greater than five years demonstrated a marked slowing of speech rate and a further deterioration on the measures of the laryngeal control. Involvement of tongue, lip, and palatal movements occurs in the later stages of Shy Drager syndrome. Shy Drager syndrome patients may be considered dysarthric only in the advanced stages of the disease, even though speech symptoms reflecting vocal fold incompetence appear early. Further longitudinal studies are needed to determine the precise pattern of breakdown in the motor speech system in this syndrome.

\section{References}

' Bradbury S, Eggleston C. Postural hypotension. Am Heart J 1925;1:73-86.

${ }^{2}$ Polinsky RJ. Neurogenic orthostatic hypotension: concepts in diagnosis and management. IM-Internal Med for the Specialist 1983;4:120-37.

${ }^{3}$ Shy G, Drager GA. A neurological syndrome associated with orthostatic hypotension: A clinical-pathological study. Arch Neurol 1960;2:511-27.

${ }^{4}$ Thomas JE, Schirger A, Fealey RD, Sheps SG. Orthostatic hypotension. Mayo Clin Proc 1981;56:117-25.

${ }^{5}$ Spokes EGS, Bannister R, Oppenheimer DR. Multiple system atrophy with autonomic failure. J Neurol Sci 1979;43:59-82.

${ }^{6}$ Kontos HA, Richardson DW, Norvell JE. Norepinephrine depletion in idiopathic orthostatic hypotension. $N$ Engl J Med 1975;82:336-41.

${ }^{7}$ Polinsky RJ, Kopin IJ, Ebert MH, Weise V. Pharmacologic distinction of different orthostatic hypotension syndromes. Neurology (NY) 1981;31:1-7.

${ }^{8}$ Hanson DG, Ludlow CL, Bassich CJ. Vocal fold paresis in Shy Drager syndrome. Ann Otol Rhino Laryngolog 1983;92: 85-90.

' Williams A, Hanson D, Calne DB. Vocal cord paralysis in the Shy Drager syndrome. J Neurol Neurosurg Psychiatry 1979;42:151-3.

${ }^{10}$ Teravainen H, Udd B. Vocal cord paralysis in the Shy Drager syndrome. Acta Neurol Scand 1982;66:505-7.

"Guindi GM, Bannister R, Gibson WPR, Payne JK. Laryngeal electromyography in multiple system atrophy with autonomic failure. Ann Otol Rhino Laryngology 1981;44:49-53.

12 Bannister R, Gibson W, Michaels L, Oppenheimer D. Laryngeal abductor paralysis in multiple systems atro- 
phy. Brain 1981;104:351-68.

${ }^{13}$ Linebaugh C. The dysarthrias of Shy Drager syndrome.J Speech Hear Dis 1979;44:55-60.

${ }^{14}$ Thomas JE, Shirger A. Neurologic manifestations in idiopathic orthostatic hypotension. Arch Neur 1963; 8:204-8.

${ }^{15}$ Ludlow CL, Bassich CJ. The results of acoustic and perceptual assessment of two types of dysarthria. In: Berry W. ed. Clinical Dysarthria. San Diego: College-Hill Press 1983.

${ }^{16}$ Ludlow CL, Bassich CJ. Relationships between perceptual ratings and acoustic measures of hypokinetic

\section{Appendix}

Definition of Acoustic Measures

Name of measure

Rate control

1. Time of Regular Rate Sentence Production

2. Time of Fast Rate Sentence Production

3. Difference in Time Between Regular and Fast Sentence Rates

4. Change in Rate for Repetition of syllable /pa/

5. Latency in Initiation of Vowel /a/

Speech articulation

6. Lip vs Tongue Phonations

7. Tongue Blade vs Back Phonations

8. Change in Number of Monosyllabic vs Bisyllabic Phoneme Repetititions

9. Change in Number of Vowel vs Consonant Phoneme Repetitions

10. Change in Initiation of Speech Between Vowel /a/ vs Bilabial Syllable /ba/

11. Difference in Initiation of Speech Between Vowel/a/ vs Velar CV Syllable /ga/

Voicing control:

12. Total Number of Voicing Errors for Vowel Repetitions

13. Total Number of Voicing Errors for Consonant Repetitions speech. In: McNeil MR, Rosenbek JC, Aronson AE. eds. Dysarthria of Speech: Physiology-AcousticsLinguistics-Management. San Diego: College-Hill Press 1983.

17 American National Standards Institute Specification for audiometers (ANSI 3.6) New York: American National Standards Institute 1969.

${ }^{1 *}$ Winer BJ. Statistical Principles in Experimental Design. New York: McGraw-Hill 1971.

${ }^{19} \mathrm{Nie} \mathrm{NH}$, Hill CH, Jenkins JG Steinbrenner K, Bent DH. Statistical Package for the Social Sciences. New York: McGraw-Hill 1975.

\section{Definition of measure}

Total time (in seconds) for the regular rate productions of Sentences A and B.

Total time (in seconds) for the fast rate productions of Sentences $A$ and $B$.

Time (in seconds) for sentence production at regular rate minus time at fast rate.

Number of syllables in last $1.5 \mathrm{~s}$ minus number of syllables in first $1.5 \mathrm{~s}$ during a $5.5 \mathrm{~s}$ period of repetition of the syllable /pa/. Negative values reflect a decreasing rate of repetition.

Number of milliseconds between click initiation and onset of phonation of the vowel $/ \mathrm{a} /$.

Average number of voicing offsets occurring within a 5 second period for $/ \mathrm{ta} /$ and $/ \mathrm{ka} /$ syllable repetitions minus the number of voicing offsets for $/ \mathrm{pa}$ repetitions.

Average number of voicing offsets occurring within a $5 \mathrm{~s}$ period for $/ \mathrm{ta} /$ syllable repetitions minus number of voicing offsets for $/ \mathrm{ka} /$ repetitions.

Change in Rate during a $5.5 \mathrm{~s}$ repetition of the syllable $/ \mathrm{pa} /$ minus the change in rate during a $5.5 \mathrm{~s}$ repetition of the syllables /pa-ta/.

Change in rate during a $5.5 \mathrm{~s}$ repetition of the vowel /a/ minus the change in rate during a $5.5 \mathrm{~s}$ repetition of the syllable $/ \mathrm{pa}$.

Number of milliseconds between click initiation and onset of phonation of the syllable /ba/ minus the number of milliseconds between click initiation and onset of phonation of the vowel $/ a$ /.

Number of milliseconds between click initiation and onset of the phonation of the syllable /ga/ minus the number of milliseconds between click initiation and onset of phonation of the vowel $/ a$ /

The total number of vowel repetitions of $/ \mathrm{a} /, / \mathrm{i} /, / \mathrm{iu} /$ and /ua/ minus the total number of phonatory offsets occurring within these four repetitions; measured within a $5 \mathrm{~s}$ interval.

The total number of consonant repetitions for the syllables $/ \mathrm{pa} /, / \mathrm{ta} /, / \mathrm{ka} /, / \mathrm{pa}-\mathrm{ta} /$ and $/ \mathrm{pa}-\mathrm{ka} /$ minus the total number of phonatory offsets occurring within these syllable repetitions, measured within a $5 \mathrm{~s}$ interval. 
14. Voicing Differences for Repetition of Vowel Syllables /iu/ vs /ua/

15. Voịcing Differences Between Tense /i/ vs Lax/a/ Vowel Syllable

16. Number of Voicing Changes During Repetitions of Vowel /a/

17. Number of Voicing Changes During Repetitions of the Syllable /pa/

Fundamental frequency control

18. Average $F_{0}$ in sentences

19. $F_{0}$ range

20. $F_{a}$ Variation in Sentence (C)

21. $F_{0}$ Change for Stress Contrasts Sentence (D)

22. $F_{0}$ for Stress Contrasts

Stress timing control

23. Inter-word Interval Length

24. Inter-syllable Interval Length

25. Change in Interval Length to Achieve Linguistic Contrast

Intensity control

26. Phonation Length

27. Average Intensity in Sentences

28. Soft to Shout Intensity Range

29. Soft to Loud Intensity Range

30. Maximum Intensity Level
Total number of phonatory offsets occurring within a $5 \mathrm{~s}$ repetition of the syllable /ua/ minus the number of phonatory offsets occurring during a $5 \mathrm{~s}$ repetition of the syllable /iu/.

Total number of phonatory offsets occurring within a $5 \mathrm{~s}$ repetition of the syllable / $\mathrm{a} /$ minus the number of phonatory offsets occurring within a $5 \mathrm{~s}$ repetition of the syllable /i/.

Total number of phonatory offsets which occur during a $5 \mathrm{~s}$ repetition of the syllable $/ \mathrm{a} /$.

Total number of phonatory offsets which occur during a $5 \mathrm{~s}$ repetition of the syllable $/ \mathrm{pa} /$.

Average of peak $F_{0}$ (measured in herts) on six nouns in three sentences $\left(D_{1}, E_{1}\right.$, and $\left.F_{1}\right)$.

Difference in hertz between low and high points of an ascending vowel production divided by the average $F_{0}$ in sentences.

Average of high and low $F_{0}$ differences in intonation contour of Sentence $C$, divided by average $F_{0}$ in sentences (in hertz).

Differences in peak $F_{0}$ (measured in hertz) between two words of equal stress minus the difference in peak $F_{0}$ between words of unequal stress, divided by the average $F_{0}$ in sentences.

(D) is the $F_{0}$ change for the words "bluebell" vs "bluebell", $(F)$ is the $F_{0}$ change for the words "cross word" vs "crossword".

Difference between initiation of equally stressed nouns in sentences $D_{1}$ and $E_{1}$, measured in seconds.

Differences between initiation of syllables in compound nouns in sentences $D_{2}$ and $E_{2}$, measured in seconds.

Difference between interval for initiation of equally stressed nouns in sentence $F_{1}$ minus interval between initiation times of syllables in compound nouns in Sentence $F_{2}$, measured in seconds.

Total length in seconds for extended vowel productions of $/ \mathrm{a} /$ and $/ \mathrm{i} /$ produced at comfortable intensity and $\mathrm{F}_{0}$.

Average of peak sound pressure level on final words in six sentences, measured in $\mathrm{dB}$ re: $20 \mu \mathrm{Pa}$.

Difference between peak sound pressure level measured in dB re: $20 \mu \mathrm{Pa}$ on "shout" production minus that on "soft" production of the vowel $/ \mathrm{a} /$.

Difference between peak sound pressure level measured in $\mathrm{dB}$ re: $20 \mu \mathrm{Pa}$ on "loud" production minus that on "soft" production of the word "no".

Peak sound pressure level in $\mathrm{dB}$ re: $20 \mu \mathrm{Pa}$ on "shout" production of the vowel $/ \mathrm{a} /$. 